\title{
Commentary: Lung cancer resection in the United States: Is regionalization the answer?
}

\author{
Benjamin D. Kozower, MD, MPH
}

\author{
From the Division of Cardiothoracic Surgery, Department of Surgery, Washington University in St Louis, St \\ Louis, Mo. \\ Disclosures: Author has nothing to disclose with regard to commercial support. \\ Received for publication Oct 1, 2019; revisions received Oct 1, 2019; accepted for publication Oct 1, 2019; \\ available ahead of print Nov 8, 2019. \\ Address for reprints: Benjamin D. Kozower, MD, MPH, Division of Cardiothoracic Surgery, Washington Univer- \\ sity in St Louis, 660 S. Euclid Ave, Campus Box 8234, St Louis, MO 63110 (E-mail: kozowerb@wustl.edu). \\ J Thorac Cardiovasc Surg 2020;159:2080 \\ $0022-5223 / \$ 36.00$ \\ Copyright (c) 2019 by The American Association for Thoracic Surgery \\ https://doi.org/10.1016/j.jtcvs.2019.10.009
}

Clark and colleagues ${ }^{1}$ have published an elegant paper in this issue of the Journal examining some nuances in the volume-outcome relationship for lung cancer. Using state-level administrative data, they evaluate the Leapfrog Group Minimal Hospital and Surgeon volume thresholds and determine the impact of age and patient risk on the outcomes of interest. Not surprisingly, their work supports the existence of a volume-outcome relationship in lung cancer and seems to validate the Leapfrog standards. Their primary findings are that hospital volume impacts surgical outcomes more than surgeon volume and that these associations are less relevant for younger, healthier patients.

The idea of regionalization for cancer care is not new, and Cancer Care Ontario performed this experiment almost 15 years ago. Results from the program, published in 2013, demonstrated very modest improvements in traditional surgical outcomes despite very high-volume standards of 150 lung cancer resections. ${ }^{2}$ They concluded that regionalization was feasible but that more data are required to validate the benefits from regionalization. Importantly, because the mortality rates of $1 \%$ to $2 \%$ are low following lung cancer resection, it's difficult to achieve the sample sizes required to see statistical differences. ${ }^{3}$

In the United States, the Society of Thoracic Surgeons has a well-established model for lung cancer resection, and hospitals can choose to participate in public reporting. ${ }^{4,5}$ Although the database is thought to represent larger programs with dedicated thoracic programs, $25 \%$ of Society of Thoracic Surgeons programs do not perform 10 lobectomies for lung cancer annually. These programs have such a low volume of cases that the models cannot reliably predict their outcomes and they are not eligible for star ratings and public reporting.

The current study moves beyond the straightforward volume analyses that we typically see by focusing on patient populations of specific interest. The study asks if there are

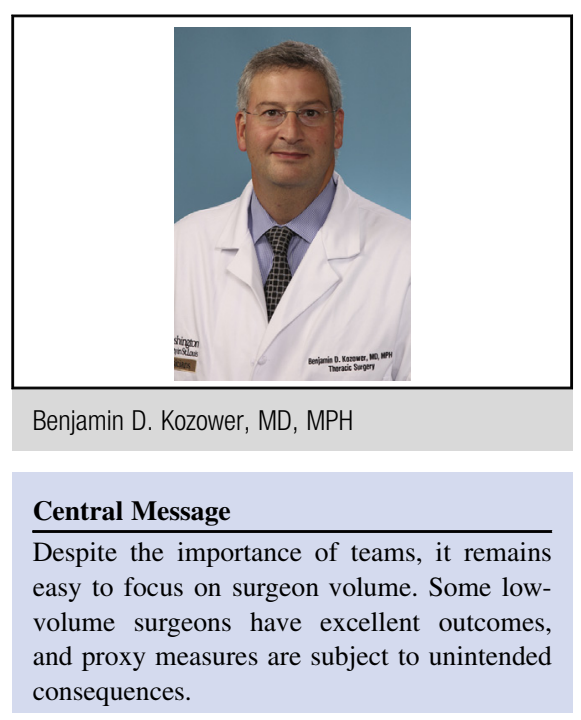

See Article page 2071.

different volume-outcome associations for young, healthy patients compared with older, sicker patients and clearly lays out the methodology used to partition the data. Not surprisingly, the volume associations are greater for the older, sicker patients, who are typically hardest to represent in predictive models. Importantly, the authors point out that the hospital volume has a greater impact on patient outcomes than surgeon volume. Despite the awareness of the importance of teams and ancillary support on patient outcomes, it remains easy for public policy to focus on surgeon volume, which is easy to measure. The authors also demonstrate that some low-volume surgeons have excellent outcomes and policies that focus on proxy measures of quality are subject to unintended consequences.

\section{References}

1. Clark JM, Cooke DT, Chin DL, Utter GH, Brown LM, Nuno M. Does one size fit all? An evaluation of the 2018 Leapfrog Group minimal hospital and surgeon volume thresholds for lung surgery. J Thorac Cardiovasc Surg. 2020;159:2071-9.e2.

2. Sundaresan S, McLeod R, Irish J, Burns J, Hunter A, Meertens E, et al. Early results after regionalization of thoracic surgical practice in a single-payer system. Ann Thorac Surg. 2013;95:472-8; discussion 478-9.

3. Dimick JB, Welch HG, Birkmeyer JD. Surgical mortality as an indicator of hospital quality: the problem with small sample size. JAMA. 2004;28:847-51.

4. Fernandez FG, Kosinski AS, Burfeind W, Park B, DeCamp MM, Seder C, et al. Cancer resection risk model: higher quality data and superior outcomes. Ann Thorac Surg. 2016;102:370-7.

5. Kozower BD, O’Brien SM, Kosinski AS, Magee MJ, Dokholyan R, Jacobs JP, et al. The Society of Thoracic Surgeons Composite Score for rating program performance for lobectomy for lung cancer. Ann Thorac Surg. 2016;101:1379-87. 